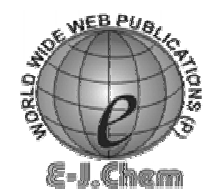

http://www.e-journals.net
ISSN: 0973-4945; CODEN ECJHAO

E-Journal of Chemistry

Vol. 5, No.2, pp. 187-200, April 2008

\title{
Kinetic, Mechanistic, Thermodynamic and Equilibrium Studies on the Adsorption of Rhodamine B by Acid Activated Low Cost Carbon
}

\author{
S.ARIVOLI* and M.THENKUZHALI \\ Department of Chemistry, M.R.Government Arts College, Mannargudi 614 001, India. \\ arivu3636@yahoo.com
}

Received 26 September 2007; Accepted 12 November 2007

\begin{abstract}
A carbonaceous adsorbent prepared from an indigenous waste by acid treatment was tested for its efficiency in removing Rhodamine B (RDB). The parameters studied include agitation time, initial dye concentration, carbon dose, $\mathrm{pH}$ and temperature. The adsorption followed first order reaction equation and the rate is mainly controlled by intra-particle diffusion. Freundlich and Langmuir isotherm models were applied to the equilibrium data. The adsorption capacity $\left(\mathrm{Q}_{\mathrm{m}}\right)$ obtained from the Langmuir isotherm plots were $51.546,47.236,44.072$ and $41.841 \mathrm{mg} / \mathrm{g}$ respectively at an initial $\mathrm{pH}$ of 7.0 at $30,40,50$ and $60^{\circ} \mathrm{C}$. The temperature variation study showed that the Rhodamine B adsorption is endothermic and spontaneous with increased randomness at the solid solution interface. Significant effect on adsorption was observed on varying the $\mathrm{pH}$ of the Rhodamine B solutions. Almost $90 \%$ removal of Rhodamine B was observed at $60{ }^{\circ} \mathrm{C}$. The Langmuir and Freundlich isotherms obtained, positive $\Delta \mathrm{H}^{0}$ value, $\mathrm{pH}$ dependent results and desorption of dye in mineral acid suggest that the adsorption of Rhodamine $\mathrm{B}$ on PSC involves physisorption mechanism.
\end{abstract}

Keywords: Activated carbon (PSC), Rhodamine B (RDB), Adsorption isotherm,

\section{Introduction}

A safe potable drinking water is necessary for every human being. Due to over population, India is suffering from persistent demand of safe drinking water. Dye and dye intermediates industries are the largest sector of chemical industries in India, since they are used in textile, paints, pulp and paper industries. More than $80 \%$ of their production is utilized by the textile industries. A huge amount of water is necessary by these industries for the cleaning and washing purposes and they discharge highly coloured effluent containing different dyes. The highly coloured effluent upsets the biological processes and even carcinogenic. Unless properly collected, treated and disposed of such type of wastewater create serious water pollution problems. 
Many investigators have studied the feasibility of using inexpensive alternative materials like pearl millet husk, date pits, saw dust, buffing dust of leather industry, coir pith, crude oil residue tropical grass, olive stone and almond shells, pine bark, wool waste, coconut shell etc., as carbonaceous precursors for the removal of dyes from water and wastewater ${ }^{1-3}$.

The present study undertaken to evaluate the efficiency of a carbon adsorbent prepared from acid activated Phoenix Sylvestric Carbon for removal of dye in aqueous solution. In order to design adsorption treatment systems, knowledge of kinetic and mass transfer processes is essential. In this paper, we have reported the applicability of kinetic and masstransfer models for the adsorption of Rhodamine B onto acid activated carbon.

\section{Experimental}

\section{Adsorbent Material}

The dried Phoenix Sylvestric leaves were carbonized with concentrated sulphuric acid in the weight ratio of $1: 1(\mathrm{w} / \mathrm{v})$. Heating for twelve hours in a furnace at $800{ }^{\circ} \mathrm{C}$ has completed the carbonization and activation. The resulting carbon was washed with distilled water until a constant $\mathrm{pH}$ of the slurry was reached. Then the carbon was dried for four hours at $120^{\circ} \mathrm{C}$ in a hot air oven. The dried material was ground well to a fine powder and sieved.

\section{Adsorption dynamic experiments}

\section{Batch equilibration method}

The adsorption experiments were carried out in a batch process at $30,40,50$ and $60{ }^{\circ} \mathrm{C}$ temperatures. The known weight of adsorbent material was added to $50 \mathrm{~mL}$ of the dye solutions with an initial concentration of $10 \mathrm{mg} / \mathrm{L}$ to $60 \mathrm{mg} / \mathrm{L}$. The contents were shaken thoroughly using a mechanical shaker rotating with a speed of $120 \mathrm{rpm}$. The solution was then filtered at preset time intervals and the residual dye concentration was measured.

\section{Effect of variable parameters}

\section{Dosage of adsorbents}

The various doses of the adsorbents are mixed with the dye solutions and the mixture was agitated in a mechanical shaker. The adsorption capacities for different doses were determined at definite time intervals by keeping all other factors constant.

\section{Initial concentration of dye}

In order to determine the rate of adsorption, experiments were conducted with different initial concentrations of dyes ranging from 10 to $60 \mathrm{mg} / \mathrm{L}$. All other factors have kept constant.

\section{Contact time}

The effect of period of contact on the removal of the dye on adsorbent in a single cycle was determined by keeping particle size, initial concentration, dosage, $\mathrm{pH}$ and concentration of other ions constant.

$p H$

Adsorption experiments were carried out at $\mathrm{pH} 2,3,4,5,6,7,8,9,10$ and 11 . The acidic and alkaline $\mathrm{pH}$ of the media was maintained by adding the required amounts of dilute hydrochloric acid and sodium hydroxide solutions. The parameters like particle size of the 
adsorbents, dye concentration, dosage of the adsorbent and concentration of other ions have kept constant while carrying out the experiments. The $\mathrm{pH}$ of the samples was determined using a portable $\mathrm{pH}$ meter, Systronics make. The $\mathrm{pH}$ meter was calibrated with 4.0 and 9.2 buffers.

\section{Chloride}

The experiments were done in the presence of varying chloride environments using various sodium chloride solutions. While doing the experiments, the absence of other anions has ensured.

\section{Temperature}

The adsorption experiments were performed at four different temperatures viz., 30, 40, 50 and $60^{\circ} \mathrm{C}$ in a thermostat attached with a shaker, Remi make. The constancy of the temperature was maintained with an accuracy of $\pm 0.5^{\circ} \mathrm{C}$.

\section{Zero point charge}

The $\mathrm{pH}$ at the potential of zero charge of the carbon (pHzpc) was measured using the $\mathrm{pH}$ drift method ${ }^{4}$. The $\mathrm{pH}$ of the solution was adjusted by using $0.01 \mathrm{M}$ sodium hydroxide or hydrochloric acid. Nitrogen was bubbled through the solution at $25{ }^{\circ} \mathrm{C}$ to remove the dissolved carbon dioxide. $50 \mathrm{mg}$ of the activated carbon was added to $50 \mathrm{~mL}$ of the solution. After stabilization, the final $\mathrm{pH}$ was recorded. The graphs of final $\mathrm{pH}$ versus initial $\mathrm{pH}$ used to determine the zero point charge of the activated carbon.

\section{Titration studies}

According to Boehm ${ }^{4}$ only strong acidic carboxylic acid groups are neutralized by sodium bicarbonate, where as those neutralized by sodium carbonate are thought to be lactones, lactol and carboxyl group. The weakly acidic phenolic groups only react with strong alkali, sodium hydroxide. Therefore, by selective neutralization using bases of different strength, the surface acidic functional group in carbon can be characterized both quantitatively and qualitatively. Neutralization with hydrochloric acid characterizes the amount of surface basic groups that are, for example, pyrones and chromenes. The basic properties have described to surface basic groups and the pi electron system of carbon basal planes. The results indicate that the activated carbon used may possesses acidic oxygen functional group on their surface and this is supported well by their respective zero point charge values. The results obtained from the above characterization studies are given in the Table.1.

\section{Desorption studies}

Desorption studies help to elucidate the nature of adsorption and recycling of the spent adsorbent and the dye. The effect of various reagents used for desorption are studied.

\section{Results and Discussion}

\section{Characterization of the adsorbent}

Activated carbons are a widely used adsorbent due to its high adsorption capacity, high surface area, micro porous structure and high degree of surface respectively. The wide usefulness of carbon is a result of their specific surface area, high chemical and mechanical stability. The chemical nature and pore structure usually determines the sorption activity. The physico chemical properties are listed in Table 1 
Table 1 Characteristics of the adsorbent

\begin{tabular}{lc}
\hline \multicolumn{1}{c}{ Properties } & PSC \\
\hline Particle size (mm) & 0.06 \\
Density (g/cc) & 0.3856 \\
Moisture content (\%) & 1.08 \\
Loss on ignition (\%) & 67 \\
Acid insoluble matter (\%) & 1.5 \\
Water soluble matter (\%) & 0.8 \\
$\mathrm{pH}$ of aqueous solution & 7.1 \\
$\mathrm{pH} \mathrm{zpc}_{\text {zpc }}$ & 6.2 \\
Surface groups (m equiv/g) & \\
(i) Carboxylic acid & 0.454 \\
(ii) Lactone, lactol & 0.068 \\
(iii) Phenolic & 0.085 \\
(iv) Basic (pyrones and chromenes) & 0.058 \\
\hline
\end{tabular}

\section{Effect of contact time and initial dye concentration}

The experimental results of adsorptions of at various concentrations (10, 20,30,40,50 and 60 $\mathrm{mg} / \mathrm{L}$ ) with contact time are shown in representative Figure 1. The equilibrium data were collected in Table 2 reveals that, percent adsorption decreased with increase in initial dye concentration, but the actual amount of dye adsorbed per unit mass of carbon increased with increase in dye concentration. It means that the adsorption is highly dependent on initial concentration of dye. It is because of that at lower concentration, the ratio of the initial number of dye molecules to the available surface area is low subsequently the fractional adsorption becomes independent of initial concentration. However, at high concentration the available sites of adsorption becomes fewer and hence the percentage removal of dye is dependent upon initial concentration ${ }^{5,6}$. Equilibrium have established at 60 minutes for all concentrations. Figure 1 reveals that the curves are single, smooth, and continuous, leading to saturation, suggesting the possible monolayer coverage of the dyes on the carbon surface.

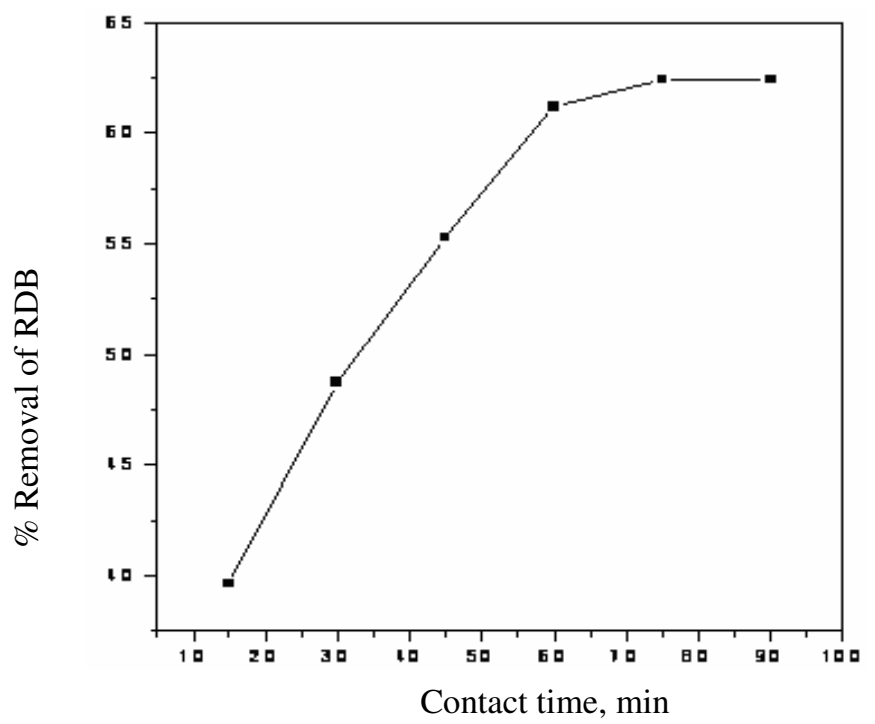

Figure 1. Effect of contact time on the removal of RDB by PSC $[\mathrm{RDB}]=30 \mathrm{mg} / \mathrm{L}$; Adsorbent dose $=\mathrm{mg} / 50 \mathrm{~mL}$ 
Table 2. Equilibrium parameters for the adsorption of Dye onto activated Carbon .

\begin{tabular}{|c|c|c|c|c|c|c|c|c|c|c|c|c|}
\hline \multirow{3}{*}[\mathrm{RDB}]{$_{0}$} & \multicolumn{4}{|c|}{$\mathrm{C}_{\mathrm{e}, \mathrm{mg} / \mathrm{L}}$} & \multicolumn{4}{|c|}{$\mathrm{Q}_{\mathrm{e}} \mathrm{mg} / \mathrm{g}$} & \multicolumn{4}{|c|}{ Dye removed, \% } \\
\hline & \multicolumn{8}{|c|}{ Temperature, ${ }^{0} \mathrm{C}$} & \multirow[b]{2}{*}{$30^{\circ}$} & \multirow[b]{2}{*}{$40^{\circ}$} & \multirow[b]{2}{*}{$50^{\circ}$} & \multirow[b]{2}{*}{$60^{\circ}$} \\
\hline & 30 & 40 & 50 & 60 & 30 & 40 & 50 & 60 & & & & \\
\hline 10 & 3.2242 & 2.8165 & 2.4028 & 2.0143 & 6.7758 & 7.1835 & 7.5972 & 7.9857 & 67.7 & 71.8 & 75.9 & 79.8 \\
\hline 20 & 6.9425 & 6.5224 & 6.1038 & 5.7044 & 13.0575 & 13.4776 & 13.8962 & 14.2956 & 65.2 & 67.3 & 69.4 & 71.4 \\
\hline 30 & 11.4628 & 11.0245 & 10.6027 & 10.2103 & 18.5372 & 18.9755 & 19.3973 & 19.7897 & 61.7 & 63.5 & 64.6 & 65.9 \\
\hline 40 & 16.8729 & 16.4633 & 16.0025 & 15.6329 & 23.1271 & 23.5367 & 23.9975 & 24.3670 & 57.8 & 58.8 & 60.0 & 60.9 \\
\hline 50 & 23.2926 & 22.8735 & 22.4632 & 22.0142 & 26.7074 & 27.1265 & 27.5368 & 27.9858 & 53.4 & 54.2 & 55.1 & 55.9 \\
\hline 60 & 29.5428 & 29.1336 & 28.7155 & 28.3847 & 30.4572 & 30.8664 & 31.2845 & 31.6153 & 50.7 & 51.4 & 52.1 & 52.6 \\
\hline
\end{tabular}




\section{Effect of carbon concentration}

The adsorption of the dyes on carbon was studied by varying the carbon concentration (25$250 \mathrm{mg} / 50 \mathrm{~mL}$ ) for $30 \mathrm{mg} / \mathrm{L}$ of dye concentration. The percent adsorption increased with increase in the carbon concentration (Figure 2). This was attributed to increased carbon surface area and availability of more adsorption sites ${ }^{5,6}$. Hence the remaining parts of the experiments are carried out with the adsorbent dose of $50 \mathrm{mg} / 50 \mathrm{~mL}$.

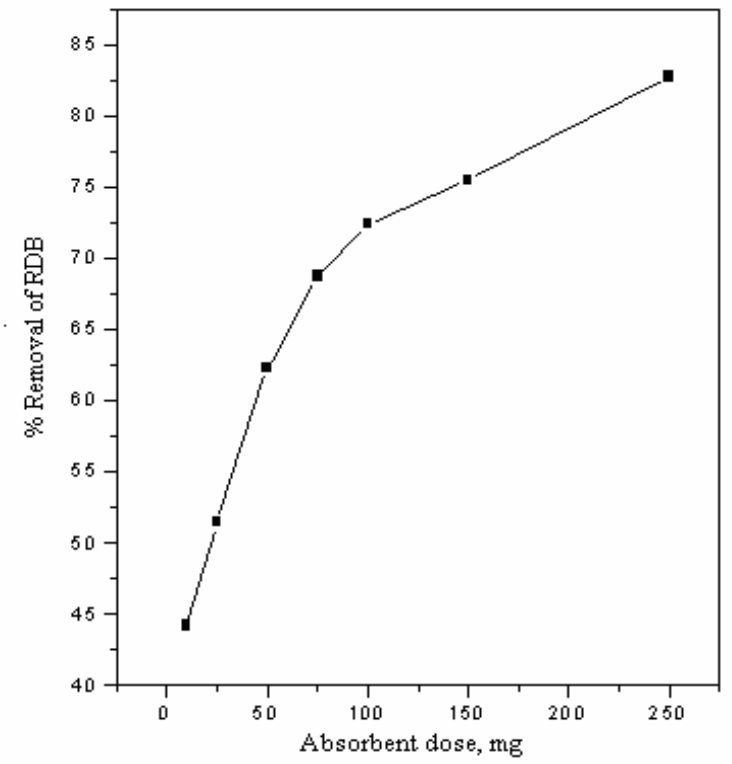

Figure 2. Effect of absorbent dose on the removal of RDB by PSC $[\mathrm{RDB}]=30 \mathrm{mg} / \mathrm{L}$; contact time $=90 \mathrm{~min}$

\section{Adsorption isotherm}

The experimental data analyzed according to the linear form of the Langmuir and Freundlich isotherms ${ }^{7,8}$. The Langmuir isotherm represented by the following equation

$$
\mathrm{C}_{\mathrm{e}} / \mathrm{Q}_{\mathrm{e}}=1 / \mathrm{Q}_{\mathrm{m}} \mathrm{b}+\mathrm{C}_{\mathrm{e}} / \mathrm{Q}_{\mathrm{m}}
$$

Where $C_{e}$ is the equilibrium concentration $(\mathrm{mg} / \mathrm{L}), Q_{e}$ is the amount adsorbed at equilibrium $(\mathrm{mg} / \mathrm{g})$ and $\mathrm{Q}_{\mathrm{m}}$ and $\mathrm{b}$ is Langmuir constants related to adsorption efficiency and energy of adsorption, respectively. The linear plots of $\mathrm{C}_{e} / \mathrm{Q}_{\mathrm{e}}$ versus $\mathrm{C}_{\mathrm{e}}$ suggest the applicability of the Langmuir isotherms (Figure.3). The values of $\mathrm{Q}_{\mathrm{m}}$ and $\mathrm{b}$ were determined from slope and intercepts of the plots and are presented in Table 3. From the results, it is clear that the value of adsorption efficiency $\mathrm{Q}_{\mathrm{m}}$ and adsorption energy $\mathrm{b}$ of the carbon increases on increasing the temperature. From the values we can conclude that the maximum adsorption corresponds to a saturated monolayer of adsorbate molecules on adsorbent surface with constant energy and no transmission of adsorbate in the plane of the adsorbent surface. The observed $b$ values shows that the adsorbent prefers to bind acidic ions and that speciation predominates on sorbent characteristics, when ion exchange is the predominant mechanism takes place in the adsorption of RDB, it confirms the endothermic nature of the process involved in the system ${ }^{9,10,11}$. To confirm the favourability of the adsorption process, the separation factor $\left(R_{L}\right)$ was calculated and presented in Table 4 . The values were found to be between 0 and 1 and confirm that the ongoing adsorption process is favorable ${ }^{12}$. 


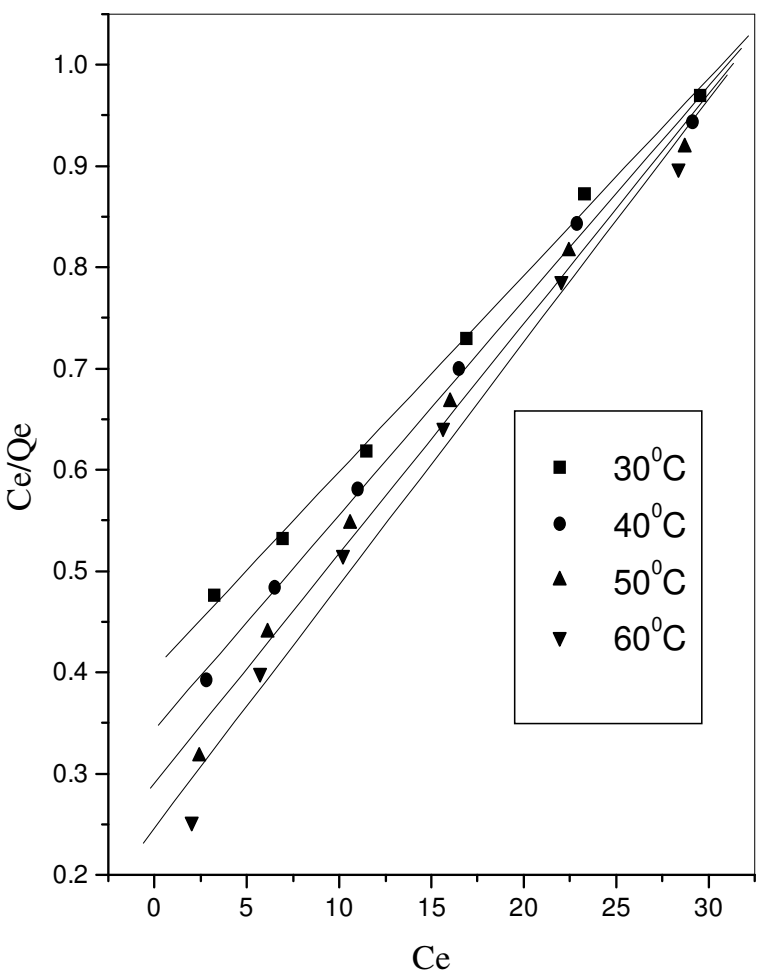

Figure 3. Langmuir adsorption isotherm for the adsorption of RDB by PSC

Table 3. Langmuir isotherm results

\begin{tabular}{lcccc}
\hline Dye & Temp & \multicolumn{3}{c}{ Statistical parameters/constants } \\
\cline { 3 - 5 } & ${ }^{0} \mathrm{C}$ & $\mathrm{r}^{2}$ & $\mathrm{Q}_{\mathrm{m}}$ & $\mathrm{b}$ \\
\hline RDB & 30 & 0.9986 & 51.546 & 0.0480 \\
& 40 & 0.9982 & 47.236 & 0.0615 \\
& 50 & 0.9925 & 44.072 & 0.0781 \\
& 60 & 0.9929 & 41.841 & 0.0968 \\
\hline
\end{tabular}

Table 4. Dimensionless Separation factor $\left(\mathrm{R}_{\mathrm{L}}\right)$

\begin{tabular}{crrrr}
\hline$[\mathrm{RDB}]_{0}$ & \multicolumn{4}{c}{ Temperature, ${ }^{0} \mathrm{C}$} \\
\cline { 2 - 5 } $\mathrm{mg} / \mathrm{L}$ & 30 & 40 & 50 & 60 \\
\hline 10 & 0.675 & 0.617 & 0.561 & 0.507 \\
20 & 0.510 & 0.446 & 0.390 & 0.340 \\
30 & 0.409 & 0.349 & 0.299 & 0.255 \\
40 & 0.342 & 0.287 & 0.243 & 0.205 \\
50 & 0.294 & 0.243 & 0.204 & 0.170 \\
60 & 0.257 & 0.212 & 0.176 & 0.146 \\
\hline
\end{tabular}

The Freundlich equation was employed for the adsorption of Rhodamine B dye on the adsorbent. The Freundlich isotherm was represented by

$$
\log \mathrm{Q}_{\mathrm{e}}=\log \mathrm{K}_{\mathrm{f}}+1 / \mathrm{n} \log \mathrm{C}_{\mathrm{e}}
$$


Where $\mathrm{Q}_{\mathrm{e}}$ is the amount of Rhodamine B dye adsorbed (mg/g), $\mathrm{C}_{\mathrm{e}}$ is the equilibrium concentration of dye in solution $(\mathrm{mg} / \mathrm{L})$ and $\mathrm{K}_{\mathrm{f}}$ and $\mathrm{n}$ are constants incorporating the factors affecting the adsorption capacity and intensity of adsorption, respectively. Linear plots of $\log \mathrm{Q}_{\mathrm{e}}$ versus $\log \mathrm{C}_{\mathrm{e}}$ shows that the adsorption of Rhodamine $\mathrm{B}$ dye obeys the Freundlich adsorption isotherm (Figure.4). The values of $\mathrm{K}_{\mathrm{f}}$ and $\mathrm{n}$ given in the Table 5 shows that the increase in negative charges on the adsorbent surface that makes electrostatic force like Vanderwaal's between the carbon surface and dye ion. The molecular weight, size and radii either limit or increase the possibility of the adsorption of the dye onto adsorbent. However, the values clearly show the dominance in adsorption capacity. The intensity of adsorption is an indicative of the bond energies between dye and adsorbent and the possibility of slight chemisorptions rather than physisorption ${ }^{10,11}$. However, the multilayer adsorption of RDB through the percolation process may be possible. The values of $n$ is greater than one indicating the adsorption is much more favorable ${ }^{12}$.

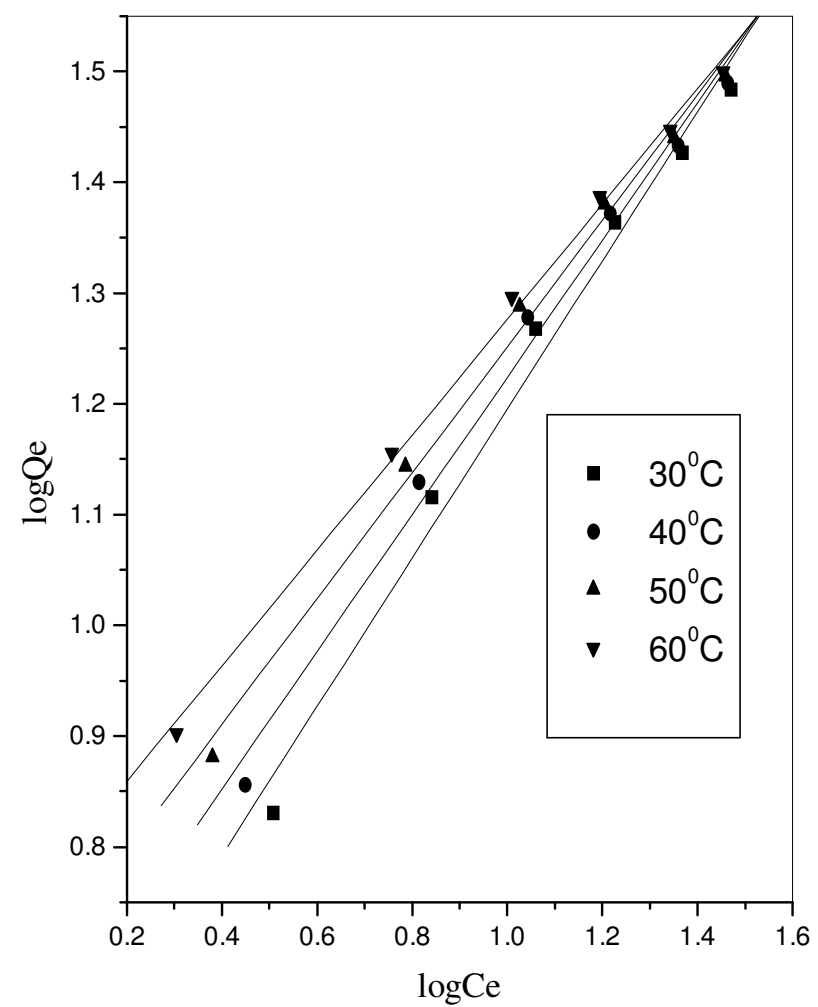

Figure 4. Freundlich adsorption isotherm for the adsorption of RDB by PSC

Table 5. Freundlich isotherm results

\begin{tabular}{ccccc}
\hline Dye & Temp & \multicolumn{3}{c}{ Statistical parameters/constants } \\
\cline { 3 - 5 } & ${ }^{0} \mathrm{C}$ & $\mathrm{r}^{2}$ & $\mathrm{~K}_{\mathrm{f}}$ & $\mathrm{n}$ \\
\hline RDB & 30 & 0.9927 & 1.9561 & 1.4903 \\
& 40 & 0.9945 & 1.8578 & 1.6144 \\
& 50 & 0.9967 & 1.7661 & 1.7580 \\
& 60 & 0.9982 & 1.6838 & 1.9190 \\
\hline
\end{tabular}




\section{Effect of temperature}

The adsorption capacity of the carbon increased with increase in the temperature of the system from $30^{\circ}-60^{\circ} \mathrm{C}$. Thermodynamic parameters such as change in free energy were determined using the following equations $\left(\Delta \mathrm{G}^{\circ}\right)(\mathrm{kJ} / \mathrm{mol})$, enthalpy $\left(\Delta \mathrm{H}^{\circ}\right)(\mathrm{kJ} / \mathrm{mol})$ and entropy $\left(\Delta \mathrm{S}^{\circ}\right)(\mathrm{J} / \mathrm{K} / \mathrm{mol})$ were determined using the following equations

$$
\begin{aligned}
& \mathrm{K}_{0}=\mathrm{C}_{\text {solid }} / \mathrm{C}_{\text {liquid }} \\
& \Delta \mathrm{G}^{\circ}=-\mathrm{RT} \ln \mathrm{K}_{\mathrm{O}} \\
& \operatorname{Iog} \mathrm{K}_{0}=\Delta \mathrm{S}^{\circ} /(2.303 \mathrm{RT})-\Delta \mathrm{H}^{\circ} /(2.303 \mathrm{RT})
\end{aligned}
$$

Where $\mathrm{K}_{\mathrm{o}}$ is the equilibrium constant, $\mathrm{C}_{\text {solid }}$ is the solid phase concentration at equilibrium $(\mathrm{mg} / \mathrm{L}), \mathrm{C}_{\text {liquid }}$ is the liquid phase concentration at equilibrium $(\mathrm{mg} / \mathrm{L}), \mathrm{T}$ is the temperature in Kelvin and $\mathrm{R}$ is the gas constant. The $\Delta \mathrm{H}^{\circ}$ and $\Delta \mathrm{S}^{\circ}$ values obtained from the slope and intercept of Van't Hoff plots have presented in Table 6. The values $\Delta \mathbf{H}^{\circ}$ are with in the range of 1 to $93 \mathrm{KJ} / \mathrm{mol}$ indicates the physisorption. From the results we could make out that physisorption is much more favorable for the adsorption of RDB. The positive values of $\Delta \mathrm{H}^{\circ}$ show the endothermic nature of adsorption and it governs the possibility of physical adsorption $^{11,13}$. Because in the case of physical adsorption, while increasing the temperature of the system, the extent of dye adsorption increases, this rules out the possibility of chemisorption $^{13}$. The low $\Delta \mathrm{H}^{\circ}$ value depicts dye is physisorbed onto adsorbent PSC.

\begin{tabular}{|c|c|c|c|c|c|c|c|c|c|c|}
\hline \multirow[t]{2}{*}[\mathrm{D}]{$_{0}$} & \multicolumn{4}{|c|}{$\begin{array}{c}\mathrm{K}_{0} \\
\text { Temperature }{ }^{0} \mathrm{C}\end{array}$} & \multicolumn{4}{|c|}{$\Delta \mathrm{G}^{\mathrm{o}}$} & \multirow[t]{2}{*}{$\Delta \mathrm{H}^{\mathrm{o}}$} & \multirow[t]{2}{*}{$\Delta \mathrm{S}^{\mathrm{o}}$} \\
\hline & 30 & 40 & 50 & 60 & 30 & 40 & 50 & 60 & & \\
\hline 10 & 2.11 & 2.55 & 3.16 & 3.96 & -1.87 & -2.43 & -3.09 & -3.81 & 17.55 & 63.95 \\
\hline 20 & 1.88 & 2.07 & 2.28 & 2.51 & -1.59 & -1.88 & -2.21 & -2.54 & 7.95 & 31.43 \\
\hline 30 & 1.62 & 1.72 & 1.83 & 1.94 & -1.21 & -1.41 & -1.62 & -1.83 & 5.02 & 20.53 \\
\hline 40 & 1.37 & 1.43 & 1.50 & 1.56 & -0.79 & -0.93 & -1.12 & -1.23 & 3.60 & 14.48 \\
\hline 50 & 1.15 & 1.19 & 1.23 & 1.27 & -0.34 & -0.44 & -0.54 & -0.66 & 2.84 & 10.49 \\
\hline 60 & 1.03 & 1.06 & 1.09 & 1.11 & -0.08 & -0.15 & -0.23 & -0.30 & 2.16 & 7.38 \\
\hline
\end{tabular}

Table 6. Equilibrium constant and thermodynamic parameters for the adsorption of Rhodamine B dye onto carbon

The negative values of $\Delta \mathrm{G}^{\circ}$ (Table 6) shows the adsorption is highly favorable and spontaneous. The positive values of $\Delta S^{\circ}$ (Table 6) shows the increased disorder and randomness at the solid solution interface of RDB with PSC adsorbent, while the adsorption there are some structural changes in the dye and the adsorbent occur. The adsorbed water molecules, which have displaced by the adsorbate species, gain more translational entropy than is lost by the adsorbate molecules, thus allowing the prevalence of randomness in the system. The enhancement of adsorption capacity of the activated carbon at higher temperatures was attributed to the enlargement of pore size and activation of the adsorbent surface $e^{12,13,14}$.

\section{Kinetics of adsorption}

The kinetics of sorption describes the solute uptake rate, which in turn governs residence time or sorption reaction. It is one of the important characteristics in defining the efficiency or sorption. In the present study, the kinetics of the dye removal was carried out to understand the behaviour of these low cost carbon adsorbents. The adsorption of dye from an aqueous follows reversible first order kinetics, when a single species are considered on a heterogeneous surface. The heterogeneous equilibrium between the dye solutions and the activated carbon are expressed as 


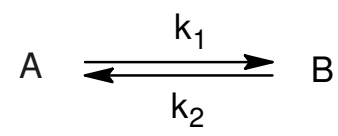

Where $\mathrm{k}_{1}$ is the forward rate constant and $\mathrm{k}_{2}$ is the backward rate constant. A represents dyes remaining in the aqueous solution and $\mathrm{B}$ represent dye adsorbed on the surface of activated carbon. The equilibrium constant $\left(\mathrm{K}_{0}\right)$ is the ration of the concentration adsorbate in adsorbent and in aqueous solution $\left(\mathrm{K}_{0}=\mathrm{k}_{1} / \mathrm{k}_{2}\right)$.

In order to study the kinetics of the adsorption process under consideration the following kinetic equation proposed by Natarajan and Khalaf as cited in literature has been employed ${ }^{1}$.

$$
\log \mathrm{C}_{0} / \mathrm{C}_{\mathrm{t}}=\left(\mathrm{K}_{\mathrm{ad}} / 2.303\right) \mathrm{t}
$$

Where $\mathrm{C}_{0}$ and $\mathrm{C}_{\mathrm{t}}$ are the concentration of the dye in (in $\mathrm{mg} / \mathrm{L}$ ) at time zero and at time $\mathrm{t}$, respectively. The rate constants $\left(\mathrm{K}_{\mathrm{ad}}\right)$ for the adsorption processes have been calculated from the slope of the linear plots of $\log \mathrm{C}_{0} / \mathrm{C}_{\mathrm{t}}$ versus $\mathrm{t}$ for different concentrations and temperatures. The determination of rate constants as described in literature given by

$$
\mathrm{K}_{\mathrm{ad}}=\mathrm{k}_{1}+\mathrm{k}_{2}=\mathrm{k} 1+\left(\mathrm{k}_{1} / \mathrm{K}_{0}\right)=\mathrm{k}_{1}\left[1+1 / \mathrm{K}_{0}\right]
$$

The overall rate constant $\mathrm{k}_{\mathrm{ad}}$ for the adsorption of dye at different temperatures are calculated from the slopes of the linear Natarajan-Khalaf plots. The rate constant values are collected in Table 7 shows that the rate constant $\left(\mathrm{k}_{\mathrm{ad}}\right)$ increases with increase in temperature suggesting that the adsorption process in endothermic in nature. Further, $\mathrm{k}_{\mathrm{ad}}$ values decrease with increase in initial concentration of the dye. In cases of strict surface adsorption a variation of rate should be proportional to the first power of concentration. However, when pore diffusion limits the adsorption process, the relationship between initial dye concentration and rate of reaction will not be linear. Thus, in the present study pore diffusion limits the overall rate of dye adsorption. The over all rate of adsorption is separated into the rate of forward and reverse reactions using the above equation. The rate constants for the forward and reverse processes are also collected in Table 7 indicate that, at all initial concentrations and temperatures, the forward rate constant is much higher than the reverse rate constant suggesting that the rate of adsorption is clearly dominant. ${ }^{1,11,13}$.

Table 7. Rate constants for the adsorption of Rhodamine $B$ dye $\left(10^{3} \mathrm{k}_{\mathrm{ad}}, \mathrm{min}^{-1}\right)$ and the

\begin{tabular}{|c|c|c|c|c|c|c|c|c|c|c|c|c|}
\hline \multirow{3}{*}[\mathrm{D}]{$_{0}$} & \multicolumn{12}{|c|}{ Temperature, ${ }^{0} \mathrm{C}$} \\
\hline & \multicolumn{4}{|c|}{$\mathrm{k}_{\mathrm{ad}}$} & \multicolumn{2}{|c|}{30} & \multicolumn{2}{|c|}{40} & \multicolumn{2}{|c|}{50} & \multicolumn{2}{|c|}{60} \\
\hline & $30^{\circ}$ & $40^{\circ}$ & $50^{\circ}$ & $60^{\circ}$ & $\mathrm{k}_{1}$ & $\mathrm{~K}_{2}$ & $\mathrm{k}_{1}$ & $\mathrm{k}_{2}$ & $\mathrm{k}_{1}$ & $\mathrm{k}_{2}$ & $\mathrm{k}_{1}$ & $\mathrm{k}_{2}$ \\
\hline 10 & 11.95 & 13.08 & 15.24 & 18.1 & 8.10 & 3.8 & 9.40 & 3.68 & 11.58 & 3.66 & 14.4 & 3.65 \\
\hline 20 & 5.61 & 6.22 & 6.31 & 6.70 & 3.66 & 1.9 & 4.19 & 2.03 & 4.39 & 1.92 & 4.79 & 1.92 \\
\hline 30 & 3.41 & 3.45 & 3.86 & 3.82 & 2.10 & 1.3 & 2.18 & 1.27 & 2.50 & 1.37 & 2.52 & 1.30 \\
\hline 40 & 2.37 & 2.37 & 2.44 & 2.95 & 1.37 & 1.0 & 1.39 & 0.98 & 1.46 & 0.98 & 1.80 & 1.15 \\
\hline 50 & 1.68 & 1.73 & 1.75 & 1.77 & 1.59 & 0.7 & 0.93 & 0.79 & 0.96 & 0.79 & 0.99 & 0.78 \\
\hline 60 & 1.34 & 1.36 & 1.36 & 1.38 & 0.68 & 0.6 & 0.70 & 0.66 & 0.71 & 0.65 & 0.73 & 0.65 \\
\hline
\end{tabular}
constants for forward $\left(10^{3} \mathrm{k}_{1}, \mathrm{~min}^{-1}\right)$ and reverse $\left(10^{3} \mathrm{k}_{2}, \min ^{-1}\right)$ process

\section{Intraparticle diffusion}

The most commonly used technique for identifying the mechanism involved in the sorption process is by fitting the experimental data in an intraparticle diffusion plot. Previous studies by various researchers showed that the plot of $Q$ versus $t^{0.5}$ represents multi linearity, which 
characterizes the two or more steps involved in the sorption process. According to Weber and Morris, an intraparticle diffusion coefficient $\mathrm{K}_{\mathrm{p}}$ is defined by the equation:

$$
\mathrm{K}_{\mathrm{p}}=\mathrm{Q} / \mathrm{t}^{0.5}
$$

Thus the $K_{\mathrm{p}}\left(\mathrm{mg} / \mathrm{g} \min ^{0.5}\right)$ value can be obtained from the slope of the plot of Qt $(\mathrm{mg} / \mathrm{g})$ versus $\mathrm{t}^{0.5}$ for Rhodamine B. From Figure 5, it was noted that the sorption process tends to be followed by two phases. The two phases in the intraparticle diffusion plot suggest that the sorption process proceeds by surface sorption and intraparticle diffusion ${ }^{15,16}$. The initial curved portion of the plot indicates a boundary layer effect while the second linear portion is due to intraparticle or pore diffusion. The slope of the second linear portion of the plot has been defined as the intraparticle diffusion parameter $\mathrm{K}_{\mathrm{p}}\left(\mathrm{mg} / \mathrm{g} \mathrm{min}{ }^{0.5}\right)$. On the other hand, the intercept of the plot reflects the boundary layer effect. The larger the intercept, the greater the contribution of the surface sorption in the rate limiting step. The calculated intraparticle diffusion coefficient $\mathrm{K}_{\mathrm{p}}$ value was given by $0.236,0.247,0.263,0.289,0.316$ and $0.343 \mathrm{mg} / \mathrm{g}$ $\min ^{0.5}$ for initial dye concentration of $10,20,30,40,50$ and $60 \mathrm{mg} / \mathrm{L}$ at $30{ }^{\circ} \mathrm{C}$.

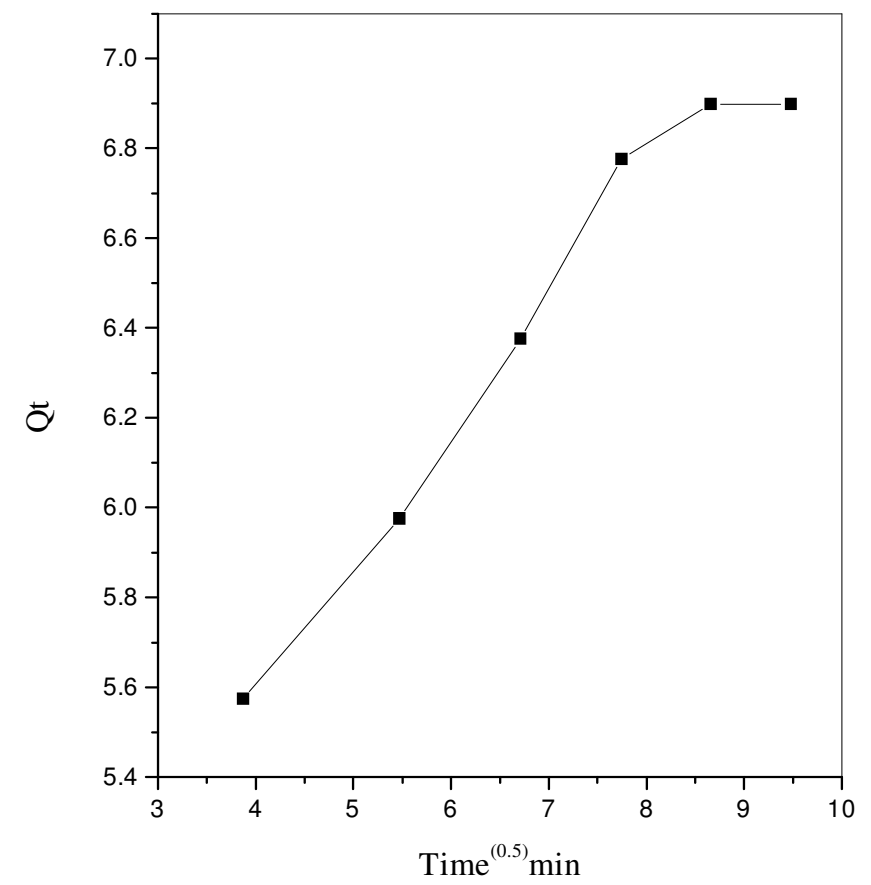

Figure 5. Intraparticle diffusion effect for the adsorption of RDB by PSC.

$[\mathrm{RDB}]=10 \mathrm{mg} / \mathrm{L} ;$ Adsorbent dose $=50 \mathrm{mg} / 50 \mathrm{~mL}$; Contact time $=90 \mathrm{~min}$

\section{Effect of $p H$}

$\mathrm{pH}$ is one of the most important parameters controlling the adsorption process. The effect of $\mathrm{pH}$ of the solution on the adsorption of RDB ions on PSC was determined. The result is shown in Figure. 6 . The $\mathrm{pH}$ of the solution was controlled by the addition of $\mathrm{HCl}$ or $\mathrm{NaOH}$. The uptake of $\mathrm{RDB}$ ions at $\mathrm{pH} 8.0$ was the minimum and a maximum in uptake was obtained at $\mathrm{pH} 2.0-6.0$. However, when the $\mathrm{pH}$ of the solution was increased (more than $\mathrm{pH}$ 9), the uptake of RDB ions was increased. It appears that a change in $\mathrm{pH}$ of the solution results in the formation of different ionic species, and different carbon surface charge. At $\mathrm{pH}$ 
values lower than 6 , the RDB ions can enter into the pore structure. At a $\mathrm{pH}$ value higher than 6, the zwitterions form of RDB in water may increase the aggregation of RDB to form a bigger molecular form (dimer) and become unable to enter into the pore structure of the carbon surface. The greater aggregation of the zwitterionic form is due to the attractive electrostatic interaction between the carboxyl and xanthane groups of the monomer.

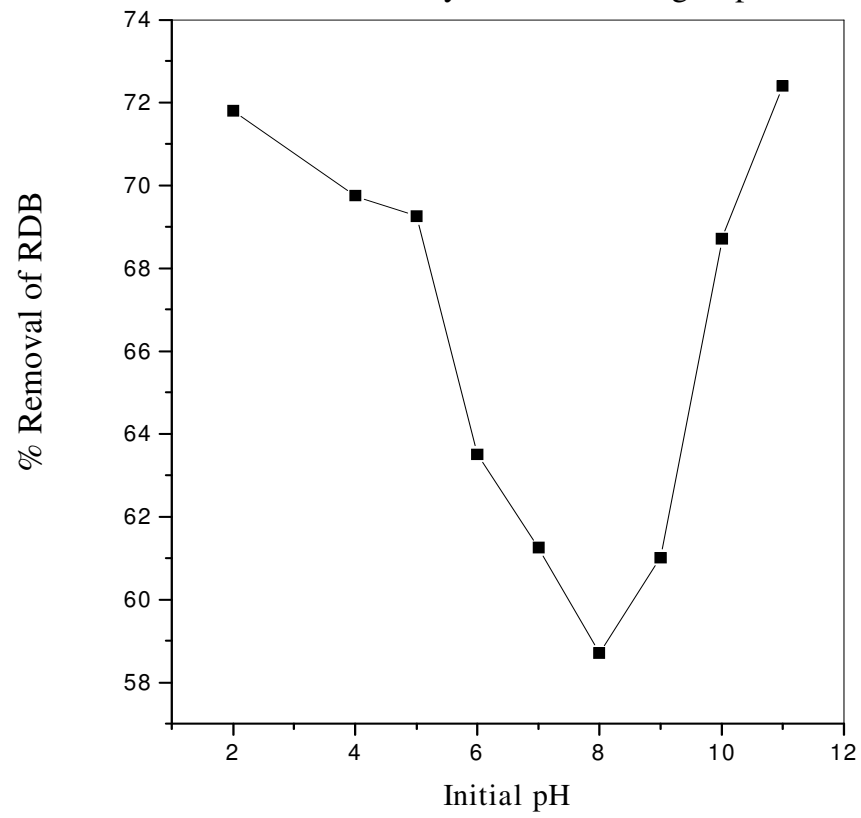

Figure 6. Effect of initial $\mathrm{pH}$ on the adsorption of RDB by PSC

$[\mathrm{RDB}]=30 \mathrm{mg} / \mathrm{L}$; Adsorbent dose $=50 \mathrm{mg} / 50 \mathrm{~mL}$; Contact time $=90 \mathrm{~min}$

At a $\mathrm{pH}$ value higher than 9 , the exisistance of $\mathrm{OH}^{-}$creates a competition between $-\mathrm{N}^{+}$ and $\mathrm{COO}^{-}$and it will decrease the aggregation of $\mathrm{RDB}$, which causes an increase in the adsorption of RDB ions on the carbon surface. The effect of the charge on the carbon surface and the electrostatic force of attraction and repulsion between the carbon surface and the RDB ions cannot explain the result ${ }^{12,17}$.

\section{Effect of the ionic strength on the adsorption of RDB on PSC}

The effect of sodium chloride on the adsorption of RDB on PSC is shown in Figure. 7. In a low solution concentration $\mathrm{NaCl}$ had little influence on the adsorption capacity. At higher ionic strength the adsorption RDB will be increased due to the partial neutralization of the positive charge on the carbon surface and a consequent compression of the electrical double layer by the $\mathrm{Cl}^{-}$anion. The chloride ion can also enhances adsorption of RDB ion onto PSC by pairing of their charges and hence reducing the repulsion between the RDB molecules adsorbed on the surface. This initiates carbon to adsorb more of positive RDB ions ${ }^{1,17}$

\section{Desorption studies}

Desorption studies help to elucidate the nature of adsorption and recycling of the spent adsorbent and the dye. If the adsorbed dyes can be desorbed using neutral $\mathrm{pH}$ water, then the attachment of the dye of the adsorbent is by weak bonds. If sulphuric acid or alkaline water desorp the dye then the adsorption is by ion exchange. If organic acids, like acetic acid can 
desorp the dye, then the dye has held by the adsorbent through chemisorption. The effect of various reagents used for desorption studies indicate that hydrochloric acid is a better reagent for desorption, because we could get more than $70 \%$ removal of adsorbed dye. The reversibility of adsorbed dye in mineral acid or base is in agreement with the $\mathrm{pH}$ dependent results obtained. The desorption of dye by mineral acids and alkaline medium indicates that the dyes were adsorbed onto the activated carbon through by physisorption mechanisms ${ }^{12,18}$.

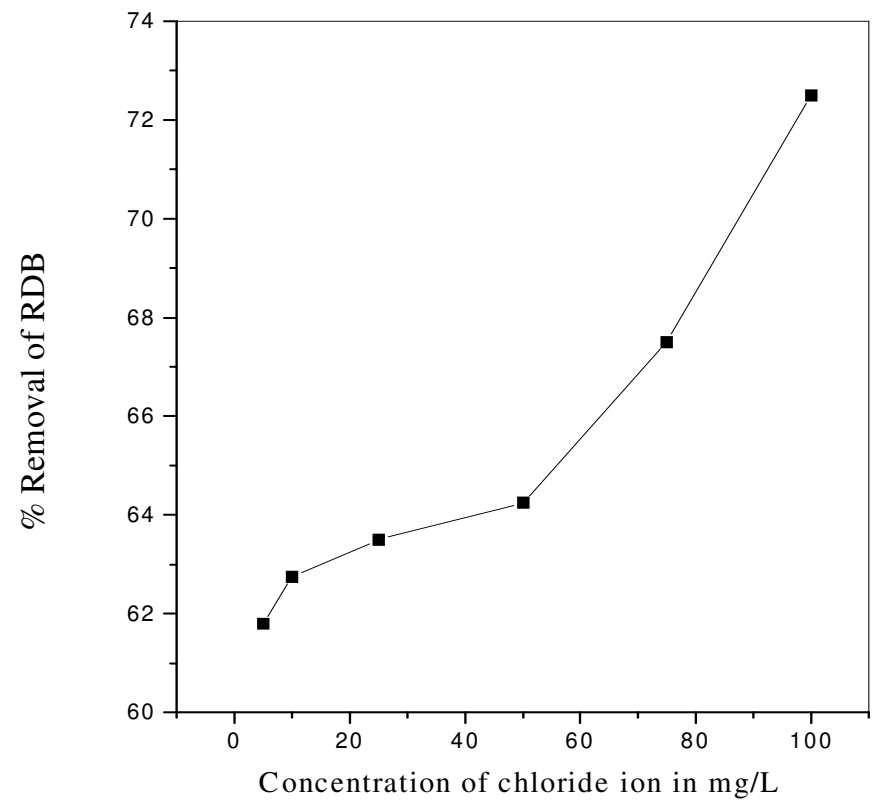

Figure 7. Effect of ionic strength on the adsorption of RDB by PSC. $[\mathrm{RDB}]=30 \mathrm{mg} / \mathrm{L}$; Adsorbent dose $=50 \mathrm{mg} / 50 \mathrm{~mL}$; Contact time $=90 \mathrm{~min}$

\section{Conclusions}

The experimental data correlated reasonably well by the Langmuir and Freundlich adsorption isotherms and the isotherm parameters were calculated. The low as well high $\mathrm{pH}$ value pay the way to the optimum amount of adsorption of the dye. The amount of Rhodamine B adsorbed increased with increasing ionic strength and increased with increase in temperature. The dimensionless separation factor $\left(\mathrm{R}_{\mathrm{L}}\right)$ showed that the activated carbon could be used for the removal of Rhodamine $\mathrm{B}$ from aqueous solution. The values of $\Delta \mathrm{H}^{\circ}, \Delta \mathrm{S}^{\circ}$ and $\Delta \mathrm{G}^{\circ}$ results shows that the carbon employed has a considerable potential as an adsorbent for the removal of Rhodamine $\mathrm{B}$.

\section{Acknowledgement}

The authors acknowledge sincere thanks to Mrs. Mala Arivoli, The Principal, M.R.Government Arts College, Mannargudi and The Director of Collegiate Education, Chennai for carrying out this research work successfully.

\section{References}

1. Arivoli S, Ph D., Thesis, Gandhigram Rural University, Gandhigram, 2007.

2. Sekaran G, Shanmugasundaram K A, Mariappan M and Raghavan K V, Indian J Chem Technol, 1995, 2, 311. 
3. Selvarani K, Ph D., Thesis, Regional Engineering College, Thiruchirapalli, 2000.

4. Jia Y F and Thomas K K, Langmuir, 2002, 18, 470-478.

5. Namasivayam C, Muniasamy N, Gayathri K, Rani M and Renganathan K, Biores Technol, 1996, 57, 37.

6. Namasivayam C and Yamuna R T, Environ Pollution, 1995, 89, 1.

7. Langmuir I, J Amer Chem Soc, 1918, 40, 1361.

8. Freundlich H, Phys Chemie, 1906, 57, 384.

9. Krishna D G and Bhattacharyya G, Appl Clay Sci, 2002, 20, 295.

10. Arivoli S, Viji Jain M and Rajachandrasekar T, Mat Sci Res India, 2006, 3, 241-250.

11. Arivoli S and Hema M, Intern J Phys Sci., 2007, 2, 10-17.

12. Arivoli S, Venkatraman B R, Rajachandrasekar T and Hema M, Res J Chem Environ. 2007, 17, 70-78.

13. Arivoli S, Kalpana K, Sudha R and Rajachandrasekar T, E-J Chem, 2007, 4, 238-254.

14. Renmin Gong, Yingzhi Sun, Jian Chen, Huijun Liu and Chao yang, Dyes and Pigments, 2005, 67, 179.

15. Vadivelan V, Vasanthkumar K, J Colloid Interf Sci, 2005, 286, 91.

16. Weber W J, Principle and Application of Water Chemistry, Edited by Faust S D and Hunter J V Wiley, New York, 1967.

17. Yupeng Guo, Jingzhu Zhao, Hui Zhang, Shaofeng Yang, Zichen Wang and Hongding $\mathrm{Xu}$, Dyes and Pigments, 2005, 66, 123-128.

18. Sreedhar M K and Anirudhan T S, Indian J Environ Protect, 1999, 19, 8. 


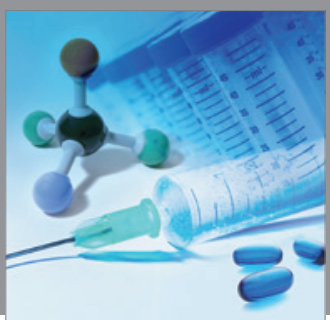

International Journal of

Medicinal Chemistry

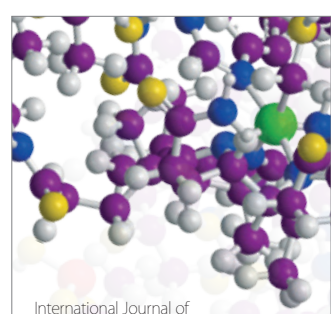

Carbohydrate Chemistry

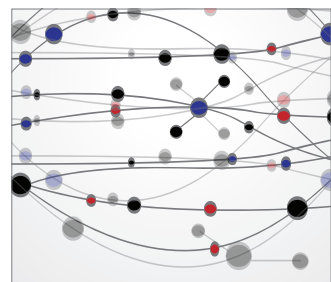

The Scientific World Journal
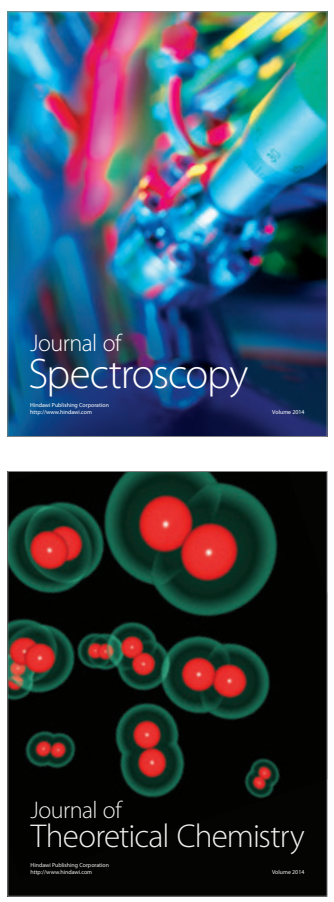
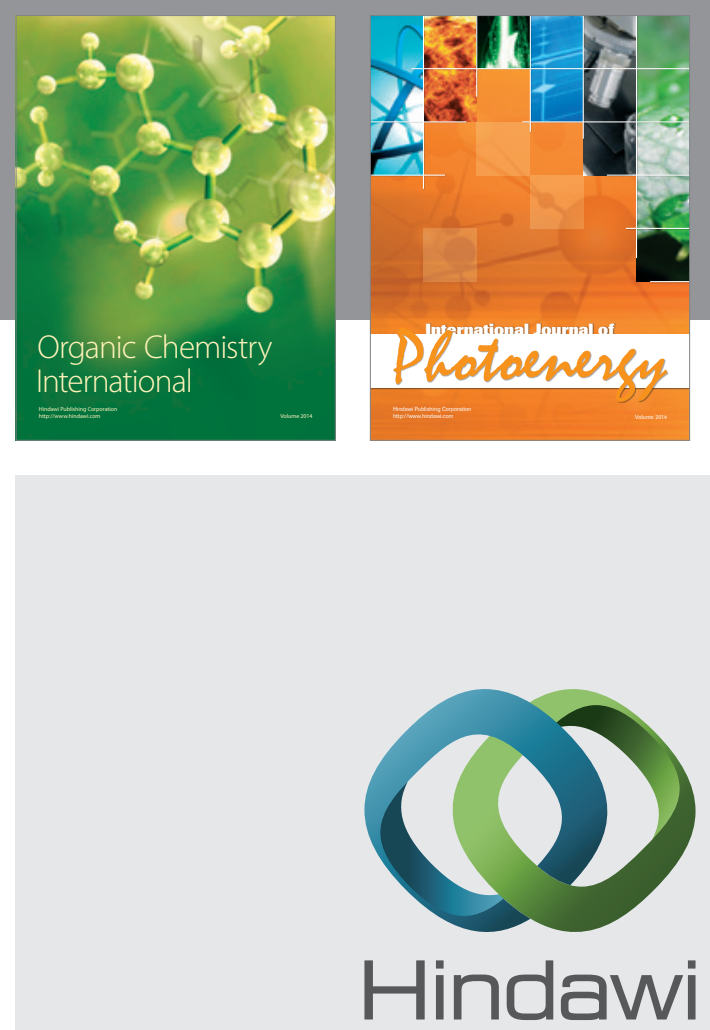

Submit your manuscripts at

http://www.hindawi.com
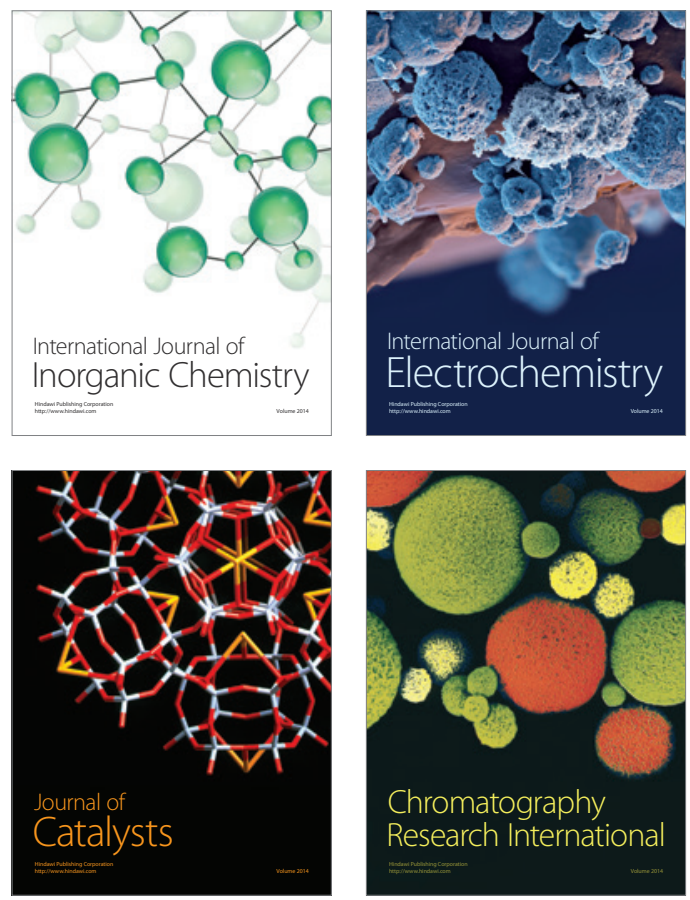
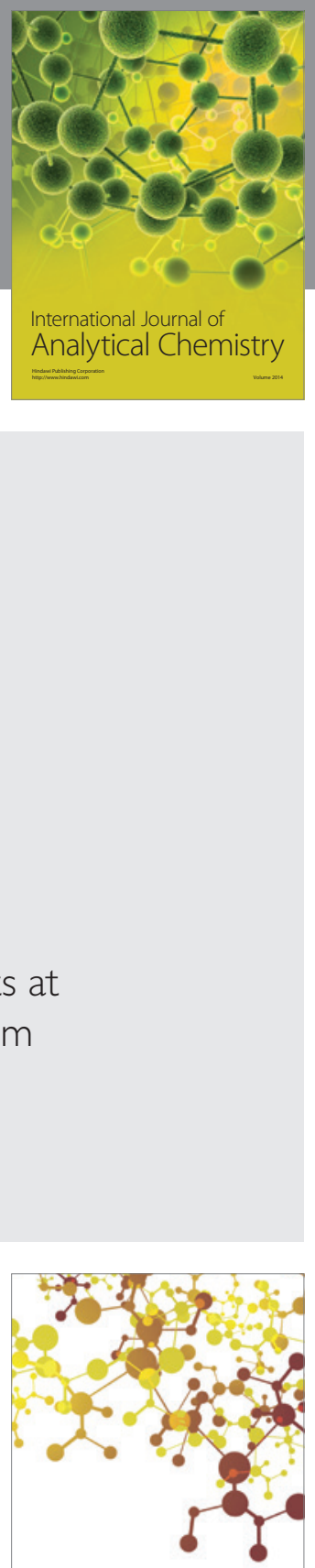

Journal of

Applied Chemistry
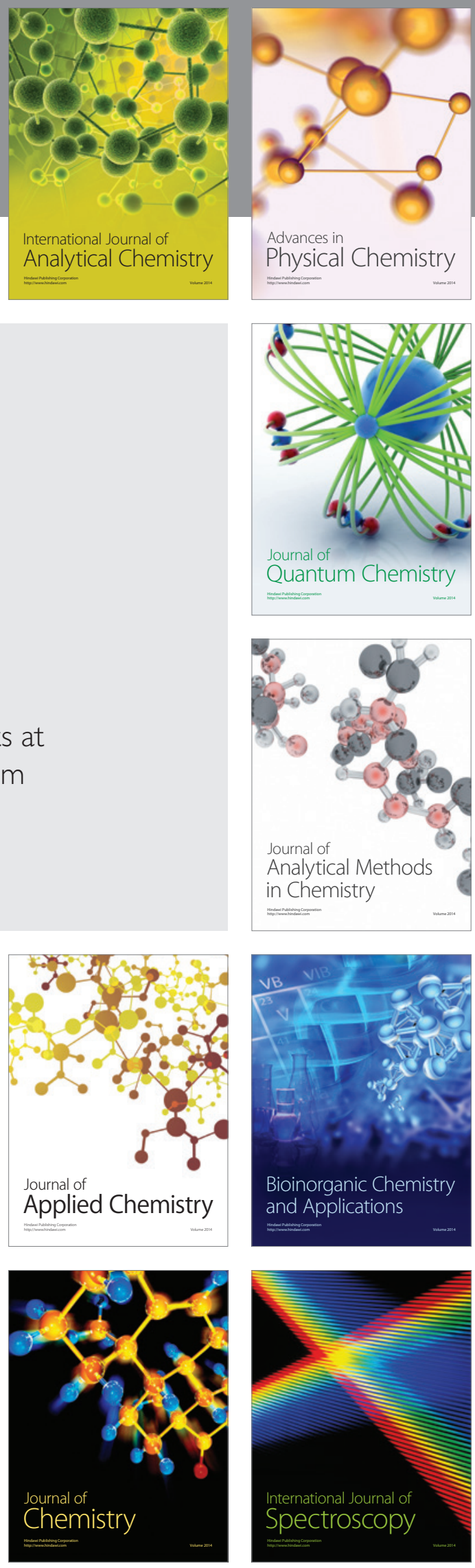